\title{
What Accounts for International Student Satisfaction in China-An Exploratory Study Based on Fuzzy AHP Approach
}

\author{
Ling Lin', Yin Luo² \\ ${ }^{1}$ School of Foreign Languages, Hubei University of Education, Wuhan, China \\ ${ }^{2}$ Economics and Management Department, China Three Gorges University, Yichang, China \\ Email: windbell621@163.com
}

How to cite this paper: Lin, L. and Luo, Y. (2021) What Accounts for International Student Satisfaction in China-An Exploratory Study Based on Fuzzy AHP Approach. Open Access Library Journal, 8: e8026.

https://doi.org/10.4236/oalib.1108026

Received: September 29, 2021

Accepted: October 26, 2021

Published: October 29, 2021

Copyright $\odot 2021$ by author(s) and Open Access Library Inc.

This work is licensed under the Creative Commons Attribution International License (CC BY 4.0).

http://creativecommons.org/licenses/by/4.0/

\begin{abstract}
China has been recruiting an increasing number of international students. Satisfaction has been held as a significant indicator of education quality, thus international student satisfaction evaluation is considered as a major means to improve education quality. In this study, a framework for evaluating international student satisfaction is constructed based on fuzzy AHP (analytical hierarchy process) in terms of student satisfaction research findings. The study finds that international students are generally happy about their higher education in China; curriculum design and service quality particularly information technology infrastructure have been emphasized as the most influential factors.
\end{abstract}

\section{Subject Areas}

Higher Education Management

\section{Keywords}

Iinternational Student Satisfaction, AHP, Fuzzy Comprehensive Evaluation

\section{Introduction}

The Chinese government's initiative of "one belt one road" aims to boost trade and cultural communication with countries. Data from the official website of the Ministry of Education of the People's Republic of China show that over 490,000 (2018) students came to China in pursuit of higher education in China. Among those international students, $12.81 \%$ of students are sponsored by the Chinese government scholarship. Chinese higher-education institutions have been en- 
couraged to enroll international students to boost higher education internationalization. A problem has arisen: how happy are those international students with their online overseas education?

Student satisfaction has been a topic in higher education research. Studies [1] explore student satisfaction since Elliot and Healy [2] put forward the concept of student satisfaction. The student satisfaction evaluation rubric is developed in light of student satisfaction research findings. The problem is that researchers have explored scarcely international student satisfaction in the context of online overseas education in China, which lends educators little help in evaluating student satisfaction. Thus this study means to fill the gap to develop a theory-based student satisfaction framework.

To explore what factors might influence international student satisfaction and to determine the weights of those factors, the fuzzy analytical hierarchy process (AHP) might serve the purpose. AHP proposed by Saaty [3] is a good method to solve multi-criteria decision-making problems. As subjective judgement might make decisions not so precise, a fuzzy set is combined with AHP [4].

The paper is divided into the following sections: Section 1 is a general introduction; Section 2 is a brief literature review of student satisfaction research and fuzzy AHP; Section 3 is to construct the framework of the international student satisfaction index system; Section 4 determines the factor and sub-factor weights; Section 5 employs fuzzy comprehensive evaluation method to make a comprehensive evaluation of international student satisfaction; Section 6 is conclusion and implication of this study.

\section{Literature Review}

\subsection{Student Satisfaction}

The concept of student satisfaction resulting from an evaluation of students' experiences was put forward by Elliot and Healy [2]. Student satisfaction was thus defined as attitude resulting from an evaluation of experiences, perceived performance, service and facilities. There have been some scales developed to investigate student satisfaction. One example is The College Student Satisfaction Scale which includes 12 to 13 indicators covering all aspects relating to American students' college life such as curriculum, life support facilities service and courses. Another example is The College Satisfaction Scale designed by the British Institute of Higher Education which focuses more on courses and learning experience. Australian College Students Satisfaction Scale intends to investigate how happy students feel about courses and campus life. Dimensions of student satisfaction are personal factors such as age, gender, preferred learning style and students' GPA and institutional factors such as instruction quality, instructor feedback, clarity of expectation, teaching style, and other factors such as classroom quality, lecturer-student relationship, interaction with fellow students, available learning equipment, library facilities and learning materials [1] [5] [6]. Wilkins and Balakrishnant [7] found that quality of lecturers, quality and availa- 
bility of resources are influential factors to account for student satisfaction in United Arab Emirates. Yusoff [8] identified dimensions(comfortable environment, student assessment and learning experience, lecture and tutorial help, textbooks and tuition fees, student support facilities, relationship with faculty, knowledgeable and responsive teachers, staff help, feedback and class size that influenced students satisfaction in Malaysian higher education setting. Research related to student satisfaction has been focusing on the qualitative way like interviews and surveys which tells little about how much each factor weighs.

\subsection{AHP (Analytical Hierarchy Process)}

The AHP approach is a structured technique for complex decision analysis based on mathematics and psychology. Satty [3] put forward AHP and refined it since. AHP has been used in numerous group-decision contexts.

Here are the steps to establish a decision-making process:

Step 1: construct the hierarchical structure for the international student satisfaction index.

Based on the literature, factors and sub-factors are identified to construct the hierarchical structure for designing the international student satisfaction index.

Step 2: identify decision-makers.

Fifteen decision-makers were identified. Decision-makers are those who are involved in international student management and teaching. They are experienced in international student management, some working faculty in the international student affairs office and some teachers. Those subjects were asked to determine the relative importance of factors and sub-factors on the basis of their experience, knowledge and expertise.

Step 3: determine the variables and conversion scale, establish a comparison matrix.

Step 4: calculate the consistency index and consistency ratio of the comparison matrix.

Consistency should be tested to ensure the reliability of group decisions.

Step 5: construct the representative matrix for all decision-makers.

Step 6: calculate weights for factors and sub-factors.

\section{Framework for International Student Satisfaction International Student Satisfaction Hierarchy}

The international student satisfaction index is hard to be determined because there are many factors involved according to the aforementioned literature. And those factors have different weights at different levels. In order to have accurate and objective evaluation results, the sources of data are international students, working staff responsible for international student affairs, and teachers. The structured index is intended to investigate opinions about international student satisfaction. In this study, the hierarchical structure of the international student satisfaction index system is derived from criteria proposed by researchers listed 
as below. The final hierarchical structure shows in Table 1.

1) Learning [9]: international students learning condition is expounded in three sub-factors: learning motivation, learning behavior and overall learning attitude. Learning is used to investigate how international students are supported in course learning from the perspective of learners.

2) Curriculum and teaching [9]: curriculum and teaching are explained in sub-factors such as teachers, curriculum design, and teaching and laboratory facilities.

Table 1. International student satisfaction hierarchical structure.

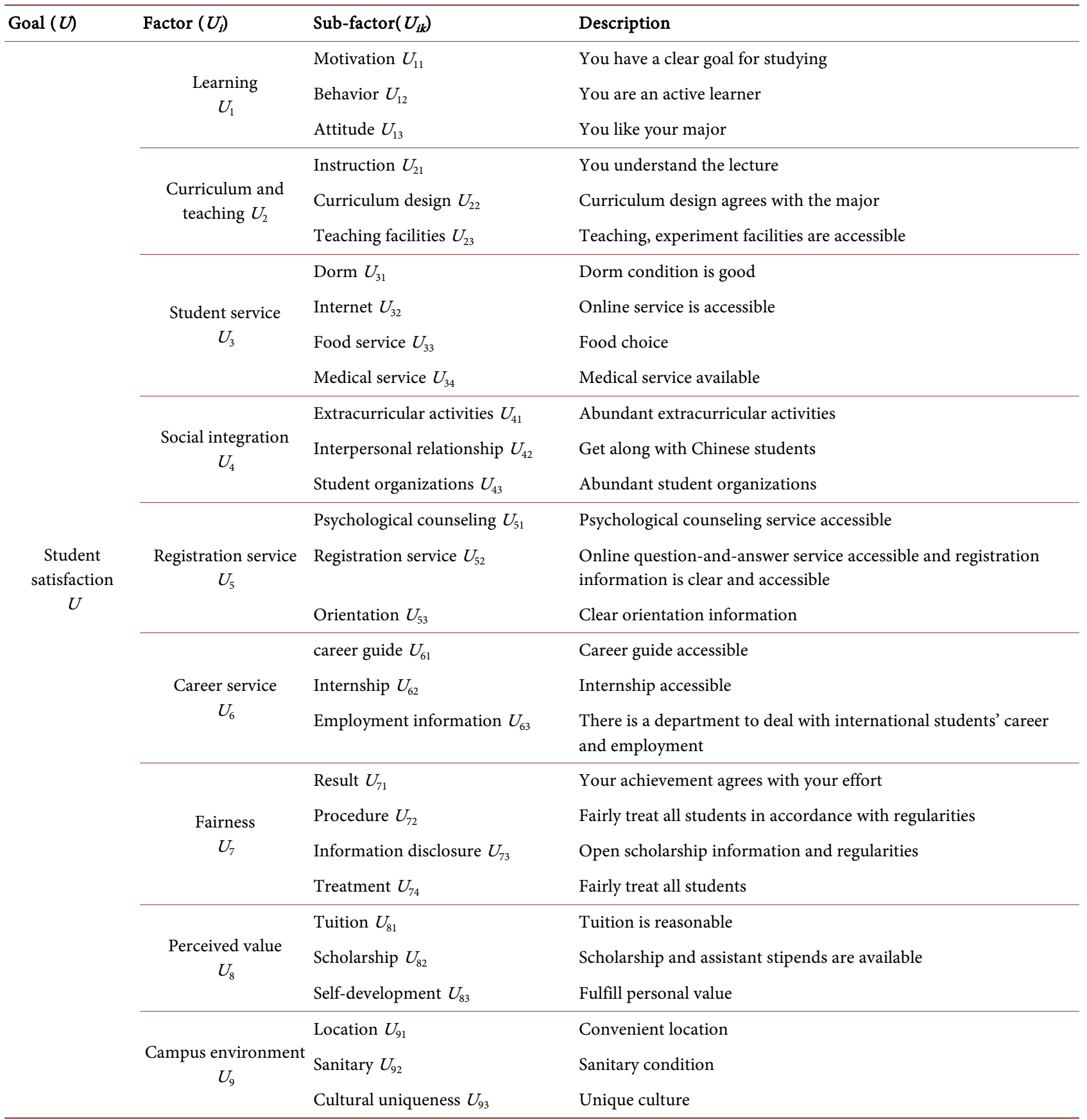


3) Student service [10]: student service is investigated in sub-factors such as dormitory condition, food service, medical service and internet service.

4) Social integration [9]: social integration is investigated in sub-factors such as extracurricular activities involvement, relationship with students and faculty, a student organization.

5) Registration service [11]: student registration service is investigated in sub-factors such as registration accessibility, orientation guide.

6) Student career service [11]: student career service is investigated in sub-factors such as career guidance, employment information service and internship information service.

7) Fairness [12]: fairness is investigated in such as university regularities, information disclosed, and equal treatment.

8) Perceived value [12]: perceived value is investigated in such as tuition, scholarship, personal development.

9) Campus environment [13] campus environment is investigated in such of campus location, sanitary condition and cultural distinctiveness.

\section{Application of AHP}

This study aims to study international students' satisfaction in a local Chinese university with the fuzzy AHP method. To ensure the accuracy of the investigation, fifteen decision-makers were cautiously selected. They are working staffs in charge of international student affairs, teachers and international students. They provided judgements based on personal experience, knowledge and perception and were asked to determine the relative importance of factors and sub-factors.

\subsection{Scales for Importance}

The decision-makers made pairwise comparisons of importance between each pair of factors. Consider a problem at a level with $n$ factors. Each set of pairwise comparisons for a level requires judgements to construct a comparison matrix. The comparison of one factor with another was conducted with questionnaires. Table 2 shows how the comparison was made in terms of different weights.

\subsection{Establishing Comparison Matrix}

Decision-makers were asked to assess the relative importance of one factor over another in provided questionnaires. The comparison matrix was obtained when making pairwise comparisons of the factors shown in Table 3.

Component heads identify the different components of your paper and are not topically subordinate to each other. Examples include Acknowledgements and References and, for these, the correct style to use is "Heading 5". Use "figure caption" for your Figure captions, and "table head" for your table title. Run-in heads, such as "Abstract", will require you to apply a style (in this case, non-italic) in addition to the style provided by the drop-down menu to differentiate the head from the text. Based on Table 3, it is concluded with a matrix for international 
Table 2. Scales for importance.

\begin{tabular}{cl}
\hline weight & Linguistic scale for the importance \\
\hline 1 & Two factors are equally important \\
3 & Compare one factor with the other, one is weakly important than the other \\
5 & Compare one factor with the other, one is obviously important than the other \\
7 & Compare one-factor $t$ with the other, one is strongly important than the other \\
9 & Compare one factor with the other, one is extremely important than the other \\
$2,4,6,8$ & Median value between neighboring factors \\
reciprocal & $a_{j i}$ refers to the importance ratio between $j$ and $i, a_{j i}=1 / a_{i j}$ \\
\hline
\end{tabular}

Table 3. Comparison matrix for international student satisfaction.

\begin{tabular}{lccccccccc}
\hline \multicolumn{1}{c}{ Satisfaction } & Learning & $\begin{array}{c}\text { Curriculum } \\
\text { and teaching }\end{array}$ & $\begin{array}{c}\text { Student } \\
\text { service }\end{array}$ & $\begin{array}{c}\text { Social } \\
\text { integration }\end{array}$ & $\begin{array}{c}\text { Registration } \\
\text { service }\end{array}$ & $\begin{array}{c}\text { Career } \\
\text { service }\end{array}$ & Fairness & $\begin{array}{c}\text { Perceived } \\
\text { value }\end{array}$ & $\begin{array}{c}\text { Environment } \\
\text { Learning }\end{array}$ \\
Curriculum and teaching & 1 & $1 / 2$ & 8 & 5 & 3 & 6 & 7 & $1 / 3$ & 9 \\
Student service & 2 & 1 & 8 & 6 & 4 & 5 & 3 & 2 & 9 \\
Social integration & $1 / 8$ & $1 / 8$ & 1 & $1 / 4$ & $1 / 7$ & $1 / 3$ & $1 / 3$ & $1 / 8$ & $1 / 2$ \\
Registration service & $1 / 5$ & $1 / 6$ & 4 & 1 & $1 / 4$ & 5 & $1 / 2$ & $1 / 6$ & 5 \\
Career service & $1 / 3$ & $1 / 4$ & 7 & 4 & 1 & 6 & 5 & $1 / 4$ & 8 \\
Fairness & $1 / 6$ & $1 / 5$ & 3 & $1 / 5$ & $1 / 6$ & 1 & $1 / 3$ & $1 / 8$ & $1 / 2$ \\
Perceived value & $1 / 7$ & $1 / 3$ & 3 & 2 & $1 / 5$ & 3 & 1 & $1 / 7$ & 5 \\
Environment & 3 & $1 / 2$ & 8 & 6 & 4 & 8 & 7 & 1 & 9 \\
\hline
\end{tabular}

student satisfaction:

$$
A_{0}=\left[\begin{array}{ccccccccc}
1 & 1 / 2 & 8 & 5 & 3 & 6 & 7 & 1 / 3 & 9 \\
2 & 1 & 8 & 6 & 4 & 5 & 3 & 2 & 9 \\
1 / 8 & 1 / 8 & 1 & 1 / 4 & 1 / 7 & 1 / 3 & 1 / 3 & 1 / 8 & 1 / 2 \\
1 / 5 & 1 / 6 & 4 & 1 & 1 / 4 & 5 & 1 / 2 & 1 / 6 & 5 \\
1 / 3 & 1 / 4 & 7 & 4 & 1 & 6 & 5 & 1 / 4 & 8 \\
1 / 6 & 1 / 5 & 3 & 1 / 5 & 1 / 6 & 1 & 1 / 3 & 1 / 8 & 1 / 2 \\
1 / 7 & 1 / 3 & 3 & 2 & 1 / 5 & 3 & 1 & 1 / 7 & 5 \\
3 & 1 / 2 & 8 & 6 & 4 & 8 & 7 & 1 & 9 \\
1 / 9 & 1 / 9 & 2 & 1 / 5 & 1 / 8 & 2 & 1 / 5 & 1 / 9 & 1
\end{array}\right]
$$

Then normalize columns of the matrix and conclude as the following:

$$
\overline{A_{0}}=\left[\begin{array}{lllllllll}
0.14 & 0.16 & 0.18 & 0.20 & 0.23 & 0.17 & 0.29 & 0.08 & 0.19 \\
0.28 & 0.31 & 0.18 & 0.24 & 0.31 & 0.14 & 0.12 & 0.47 & 0.19 \\
0.02 & 0.04 & 0.02 & 0.01 & 0.01 & 0.01 & 0.01 & 0.03 & 0.01 \\
0.03 & 0.05 & 0.09 & 0.04 & 0.02 & 0.14 & 0.02 & 0.04 & 0.11 \\
0.05 & 0.08 & 0.16 & 0.16 & 0.08 & 0.17 & 0.21 & 0.06 & 0.17 \\
0.02 & 0.06 & 0.07 & 0.01 & 0.01 & 0.03 & 0.01 & 0.03 & 0.01 \\
0.02 & 0.10 & 0.07 & 0.08 & 0.02 & 0.08 & 0.04 & 0.03 & 0.11 \\
0.42 & 0.16 & 0.18 & 0.24 & 0.31 & 0.22 & 0.29 & 0.24 & 0.19 \\
0.02 & 0.03 & 0.05 & 0.01 & 0.01 & 0.06 & 0.01 & 0.03 & 0.02
\end{array}\right]
$$


$A W=\lambda W, W$ is vector, $\lambda$ is eigenvalue of $A, W$ is the corresponding eigenvector of $\lambda$. Based on equation $A W=\lambda W$, the matrix normalization results in eigenvector $W_{0}$, $W_{0}=\left[\begin{array}{lllllllll}0.18 & 0.25 & 0.02 & 0.06 & 0.12 & 0.03 & 0.06 & 0.25 & 0.02\end{array}\right]^{\mathrm{T}}$.

Then check the consistency ratio of the comparison matrix.

$$
A_{0} W_{0}=\left[\begin{array}{ccccccccc}
1 & 1 / 2 & 8 & 5 & 3 & 6 & 7 & 1 / 3 & 9 \\
2 & 1 & 8 & 6 & 4 & 5 & 3 & 2 & 9 \\
1 / 8 & 1 / 8 & 1 & 1 / 4 & 1 / 7 & 1 / 3 & 1 / 3 & 1 / 8 & 1 / 2 \\
1 / 5 & 1 / 6 & 4 & 1 & 1 / 4 & 5 & 1 / 2 & 1 / 6 & 5 \\
1 / 3 & 1 / 4 & 7 & 4 & 1 & 6 & 5 & 1 / 4 & 8 \\
1 / 6 & 1 / 5 & 3 & 1 / 5 & 1 / 6 & 1 & 1 / 3 & 1 / 8 & 1 / 2 \\
1 / 7 & 1 / 3 & 3 & 2 & 1 / 5 & 3 & 1 & 1 / 7 & 5 \\
3 & 1 / 2 & 8 & 6 & 4 & 8 & 7 & 1 & 9 \\
1 / 9 & 1 / 9 & 2 & 1 / 5 & 1 / 8 & 2 & 1 / 5 & 1 / 9 & 1
\end{array}\right] \cdot\left[\begin{array}{l}
0.18 \\
0.25 \\
0.02 \\
0.06 \\
0.12 \\
0.03 \\
0.06 \\
0.25 \\
0.02
\end{array}\right]=\left[\begin{array}{l}
2.03 \\
2.67 \\
0.18 \\
0.58 \\
1.35 \\
0.26 \\
0.62 \\
2.81 \\
0.23
\end{array}\right]
$$

Calculate the maximum value of $\lambda, \lambda_{\max }=\sum_{i=1}^{n} \frac{(A W)_{i}}{n W_{i}} . W_{i}$ refers to one element of W. $(A W)_{i}$ represents element $i$ of $A W$, when $n=4$, it then results in

$$
\begin{aligned}
\lambda_{\max }= & \sum_{i=1}^{n} \frac{(A W)_{i}}{n W_{i}} \\
= & 1 / 9 \times(2.03 \div 0.18+2.67 \div 0.25+0.18 \div 0.02+0.58 \div 0.06+1.35 \div 0.12 \\
& +0.26 \div 0.03+0.62 \div 0.06+2.81 \div 0.25+0.23 \div 0.02) \\
= & 9.22
\end{aligned}
$$

The equation to check the consistency is $C I=\frac{\lambda_{\max }-n}{n-1}$, with consistency ratio $C R=\frac{C I}{R I}$. If $C R \leq 0.10$, the consistency is acceptable; if $C R>0.10$, the matrix has to be modified. With calculated $\lambda_{\max }=9.22$ put into consistency equation, then $C I=\frac{\lambda_{\max }-n}{n-1}=\frac{9.22-9}{9-1}=0.0275$ and $C R=\frac{C I}{R I}=0.019<0.10$, the consistency is acceptable and the matrix needs no more modification. Then it is concluded:

$$
W_{0}=\left[\begin{array}{lllllllll}
0.18 & 0.25 & 0.02 & 0.06 & 0.12 & 0.03 & 0.06 & 0.25 & 0.02
\end{array}\right]
$$

Similarly, we have:

The matrix for learning factor is:

$$
A_{1}=\left[\begin{array}{ccc}
1 & 2 & 4 \\
1 / 2 & 1 & 3 \\
1 / 4 & 1 / 3 & 1
\end{array}\right]
$$

Then we get eigenvector $W_{1}, W_{1}=\left[\begin{array}{lll}0.56 & 0.32 & 0.12\end{array}\right]$, check the consistency $\lambda_{\max }=3.02$, use the consistency equation and we get $C I=0.01$, $C R=0.019<0.10$, If $C R \leq 0.10$, the consistency is acceptable, so the matrix needs no more modification and we have $W_{1}=\left[\begin{array}{lll}0.56 & 0.32 & 0.12\end{array}\right]$. 
Similarly, we have matrix for curriculum and teaching factor.

$$
A_{2}=\left[\begin{array}{ccc}
1 & 3 & 5 \\
1 / 3 & 1 & 3 \\
1 / 5 & 1 / 3 & 1
\end{array}\right]
$$

Then calculate the eigenvector $W_{2}, W_{2}=\left[\begin{array}{lll}0.63 & 0.26 & 0.11\end{array}\right]$, check the consistency $\lambda_{\max }=3.04$, use the consistency equation and we get $C I=0.02$, $C R=0.036<0.10$, If $C R \leq 0.10$, the consistency is acceptable, so the matrix needs no more modification and we have $W_{2}=\left[\begin{array}{lll}0.63 & 0.26 & 0.11\end{array}\right]$.

In a similar way, the matrix of student service is:

$$
A_{3}=\left[\begin{array}{cccc}
1 & 4 & 2 & 5 \\
1 / 4 & 1 & 1 / 3 & 3 \\
1 / 2 & 3 & 1 & 4 \\
1 / 5 & 1 / 3 & 1 / 4 & 1
\end{array}\right]
$$

Then calculate the eigenvector $W_{3}, W_{3}=\left[\begin{array}{llll}0.48 & 0.14 & 0.30 & 0.07\end{array}\right]$, check the consistency $\lambda_{\max }=4.12$, use the consistency equation and we get $C I=0.04$, $C R=0.045<0.10$, If $C R \leq 0.10$, the consistency is acceptable, so the matrix needs no more modification and we have $W_{3}=\left[\begin{array}{llll}0.48 & 0.14 & 0.30 & 0.07\end{array}\right]$.

Similarly, the matrix for social integration is:

$$
A_{4}=\left[\begin{array}{ccc}
1 & 4 & 3 \\
1 / 4 & 1 & 1 / 2 \\
1 / 3 & 2 & 1
\end{array}\right]
$$

Then calculate the eigenvector $W_{4}, W_{4}=\left[\begin{array}{lll}0.62 & 0.14 & 0.24\end{array}\right]$, check the consistency $\lambda_{\max }=3.02$, use the consistency equation and we get $C I=0.01$, $C R=0.019<0.10$, If $C R \leq 0.10$, the consistency is acceptable, so the matrix needs no more modification and we have $W_{4}=\left[\begin{array}{lll}0.62 & 0.14 & 0.24\end{array}\right]$.

Similarly, the matrix for registration service is:

$$
A_{5}=\left[\begin{array}{ccc}
1 & 1 / 8 & 1 / 6 \\
8 & 1 & 3 \\
6 & 1 / 3 & 1
\end{array}\right]
$$

Then calculate the eigenvector $W_{5}, W_{5}=\left[\begin{array}{lll}0.06 & 0.65 & 0.29\end{array}\right]$, check the consistency $\lambda_{\max }=3.07$, use the consistency equation and we get $C I=0.035$, $C R=0.067<0.10$, If $C R \leq 0.10$, the consistency is acceptable, so the matrix needs no more modification and we have $W_{5}=\left[\begin{array}{lll}0.06 & 0.65 & 0.29\end{array}\right]$.

Similarly, the matrix for career service is:

$$
A_{6}=\left[\begin{array}{ccc}
1 & 3 & 1 / 3 \\
1 / 3 & 1 & 1 / 5 \\
3 & 5 & 1
\end{array}\right]
$$

Then calculate the eigenvector $W_{6}, W_{6}=\left[\begin{array}{lll}0.26 & 0.11 & 0.63\end{array}\right]$, check the consistency $\lambda_{\max }=3.04$, use the consistency equation and we get $C I=0.02$, $C R=0.036<0.10$, If $C R \leq 0.10$, the consistency is acceptable, so the matrix 
needs no more modification and we have $W_{6}=\left[\begin{array}{lll}0.26 & 0.11 & 0.63\end{array}\right]$.

Similarly, the matrix for fairness is:

$$
A_{7}=\left[\begin{array}{cccc}
1 & 5 & 3 & 2 \\
1 / 5 & 1 & 1 / 3 & 1 / 4 \\
1 / 3 & 3 & 1 & 1 / 3 \\
1 / 2 & 4 & 3 & 1
\end{array}\right]
$$

Then calculate the eigenvector $W_{7}, W_{7}=\left[\begin{array}{llll}0.46 & 0.07 & 0.16 & 0.31\end{array}\right]$, check the consistency $\lambda_{\max }=4.11$, use the consistency equation and we get $C I=0.037$, $C R=0.041<0.10$, If $C R \leq 0.10$, the consistency is acceptable, so the matrix needs no more modification and we have $W_{7}=\left[\begin{array}{llll}0.46 & 0.07 & 0.16 & 0.31\end{array}\right]$.

Similarly, the matrix for perceived value is:

$$
A_{8}=\left[\begin{array}{ccc}
1 & 3 & 1 / 7 \\
1 / 3 & 1 & 1 / 9 \\
7 & 9 & 1
\end{array}\right]
$$

Then calculate the eigenvector $W_{8}, W_{8}=\left[\begin{array}{lll}0.15 & 0.07 & 0.78\end{array}\right]$, check the consistency $\lambda_{\max }=3.08$, use the consistency equation and we get $C I=0.04$, $C R=0.077<0.10$, If $C R \leq 0.10$, the consistency is acceptable, so the matrix needs no more modification and we have $W_{8}=\left[\begin{array}{lll}0.15 & 0.07 & 0.78\end{array}\right]$.

Similarly, the matrix for campus environment is:

$$
A_{9}=\left[\begin{array}{ccc}
1 & 5 & 3 \\
1 / 5 & 1 & 1 / 4 \\
1 / 3 & 4 & 1
\end{array}\right]
$$

Then calculate the eigenvector $W_{9}, W_{9}=\left[\begin{array}{lll}0.62 & 0.10 & 0.28\end{array}\right]$, check the consistency $\lambda_{\max }=3.09$, use the consistency equation and we get $C I=0.045$, $C R=0.086<0.10$, If $C R \leq 0.10$, the consistency is acceptable, so the matrix needs no more modification and we have $W_{9}=\left[\begin{array}{lll}0.62 & 0.10 & 0.28\end{array}\right]$.

\subsection{Ranking Based on Weight Calculation}

Based on weight calculation, then factor and sub-factor can be ranked accordingly as shown in Table 4.

The results show that sub-factor such as learning motivation, instruction, dorms, registration service, employment information, ex-curricular activities, treatment, self-development, location are major factors that influence international students' satisfaction.

\section{Fuzzy Evaluation of International Student Satisfaction}

A fuzzy comprehensive evaluation is a mathematical method to evaluate things that are not clearly defined. It uses fuzzy transformation and maximum membership degree by evaluating factors to make a comprehensive evaluation. It is thus considered to be an efficient evaluation method to evaluate objects which are influenced by factors. 
Table 4. Factor and sub-factor ranking.

\begin{tabular}{|c|c|c|c|c|}
\hline Goal & Factor & Sub-factor & Weight & Ranking \\
\hline & \multirow{3}{*}{ Learning 0.18} & Motivation & 0.56 & 0.101 \\
\hline & & Behavior & 0.32 & 0.058 \\
\hline & & Attitude & 0.12 & 0.022 \\
\hline & \multirow{3}{*}{ Curriculum and teaching 0.25} & Instruction & 0.63 & 0.158 \\
\hline & & Curriculum design & 0.26 & 0.065 \\
\hline & & Teaching facilities & 0.11 & 0.028 \\
\hline & \multirow{4}{*}{ Student service 0.02} & Dorm & 0.48 & 0.010 \\
\hline & & Internet & 0.14 & 0.003 \\
\hline & & Food service & 0.31 & 0.006 \\
\hline & & Medical service & 0.07 & 0.001 \\
\hline & & Excurricular activities & 0.62 & 0.037 \\
\hline & Social integration 0.06 & Interpersonal relationship & 0.14 & 0.008 \\
\hline & & Student organizations & 0.24 & 0.014 \\
\hline & & Psychological counselling & 0.06 & 0.007 \\
\hline \multirow{15}{*}{$\begin{array}{c}\text { International } \\
\text { student satisfaction }\end{array}$} & Registration service 0.12 & Registration service & 0.65 & 0.078 \\
\hline & & Orientation & 0.29 & 0.035 \\
\hline & & career guide & 0.26 & 0.008 \\
\hline & Career service 0.03 & Internship & 0.11 & 0.003 \\
\hline & & Employment information & 0.62 & 0.019 \\
\hline & \multirow{4}{*}{ Fairness 0.07} & Result & 0.46 & 0.032 \\
\hline & & Procedure & 0.07 & 0.005 \\
\hline & & Information disclosure & 0.16 & 0.011 \\
\hline & & Treatment & 0.31 & 0.022 \\
\hline & \multirow{3}{*}{ Perceived value 0.25} & Tuition & 0.15 & 0.038 \\
\hline & & Scholarship & 0.07 & 0.018 \\
\hline & & Self-development & 0.78 & 0.195 \\
\hline & \multirow{3}{*}{ Environment 0.02} & Location & 0.62 & 0.012 \\
\hline & & Sanitary & 0.10 & 0.002 \\
\hline & & Cultural uniqueness & 0.28 & 0.006 \\
\hline
\end{tabular}

Step 1: In Section 4, the international student satisfaction evaluation system was built and the factor and sub-factor weights were calculated with AHP approach.

Step 2: the evaluation comment set is shown by $V, V=\left(V_{1}, V_{2}, V_{3}, V_{4}, V_{5}\right)$ in Table 2. In this study, five scales (very unsatisfied, unsatisfied, neutral, satisfied, very satisfied) were set up for comments, and they correspond to $V_{1}, V_{2}, V_{3}, V_{4}, V_{5}$ respectively. In order to make the index quantitative, five scales were valued at 1 , 


\section{$2,3,4,5$.}

Step 3: establish the single-factor evaluation matrix.

Fifteen decision-makers evaluated factors with each factor corresponding to a different weight. Based on AHP method, the comparison matrix is normalized. After calculation, nine fuzzy evaluation matrixes corresponding to each factor were constructed. $R_{1}, R_{2}, R_{3}, R_{4}, R_{5}, R_{6}, R_{7}, R_{8}, R_{9}$ respectively refers to matrixes for learning, curriculum and teaching, student service, social integration, registration service, career service, fairness, perceived value and campus environment.

$$
\begin{aligned}
& R_{1}=\left[\begin{array}{ccccc}
0 & 0 & 0.1 & 0.6 & 0.3 \\
0 & 0 & 0.3 & 0.5 & 0.2 \\
0 & 0.1 & 0.2 & 0.5 & 0.2
\end{array}\right], \quad R_{2}=\left[\begin{array}{ccccc}
0 & 0.2 & 0.3 & 0.3 & 0.2 \\
0 & 0 & 0.1 & 0.4 & 0.5 \\
0 & 0.2 & 0.3 & 0.2 & 0.3
\end{array}\right] \\
& R_{3}=\left[\begin{array}{ccccc}
0 & 0.3 & 0.2 & 0.2 & 0.3 \\
0 & 0.1 & 0.3 & 0.1 & 0.5 \\
0 & 0.3 & 0.5 & 0 & 0.2 \\
0 & 0.5 & 0.1 & 0.2 & 0.2
\end{array}\right], R_{4}=\left[\begin{array}{ccccc}
0 & 0 & 0.3 & 0.4 & 0.3 \\
0 & 0 & 0.3 & 0.4 & 0.3 \\
0 & 0.1 & 0.2 & 0.5 & 0.2
\end{array}\right] \\
& R_{5}=\left[\begin{array}{lllll}
0 & 0.1 & 0.2 & 0.2 & 0.5 \\
0 & 0.1 & 0.1 & 0.3 & 0.5 \\
0 & 0.1 & 0.1 & 0.3 & 0.5
\end{array}\right], \quad R_{6}=\left[\begin{array}{ccccc}
0 & 0.1 & 0.1 & 0.2 & 0.6 \\
0 & 0 & 0.2 & 0.2 & 0.6 \\
0 & 0 & 0.2 & 0.2 & 0.6
\end{array}\right] \\
& R_{7}=\left[\begin{array}{ccccc}
0 & 0.1 & 0 & 0.4 & 0.5 \\
0 & 0 & 0.1 & 0.3 & 0.6 \\
0 & 0 & 0.1 & 0.3 & 0.6 \\
0 & 0 & 0.1 & 0.4 & 0.5
\end{array}\right], \quad R_{8}=\left[\begin{array}{ccccc}
0 & 0.1 & 0.1 & 0.6 & 0.2 \\
0 & 0.3 & 0.4 & 0.2 & 0.1 \\
0 & 0.3 & 0.1 & 0.3 & 0.3
\end{array}\right] \\
& R_{9}=\left[\begin{array}{ccccc}
0 & 0 & 0.2 & 0.5 & 0.3 \\
0 & 0.1 & 0.3 & 0.3 & 0.3 \\
0 & 0.3 & 0.1 & 0.2 & 0.4
\end{array}\right]
\end{aligned}
$$

Step 4: produce the evaluation results.

The results of the evaluation can be obtained by multiplying the vector of the factor weight and the matrix of each factor evaluation.

$$
\begin{aligned}
B_{1} & =W_{1} R_{1}=\left(\begin{array}{lllll}
0 & 0.01 & 0.18 & 0.56 & 0.26
\end{array}\right), \\
B_{2} & =W_{2} R_{2}=\left(\begin{array}{lllll}
0 & 0.15 & 0.25 & 0.32 & 0.29
\end{array}\right), \\
B_{3} & =W_{3} R_{3}=\left(\begin{array}{lllll}
0 & 0.28 & 0.30 & 0.12 & 0.29
\end{array}\right), \\
B_{4} & =W_{4} R_{4}=\left(\begin{array}{lllll}
0 & 0.02 & 0.28 & 0.42 & 0.28
\end{array}\right), \\
B_{5} & =W_{5} R_{5}=\left(\begin{array}{lllll}
0 & 0.1 & 0.11 & 0.29 & 0.5
\end{array}\right), \\
B_{6} & =W_{6} R_{6}=\left(\begin{array}{lllll}
0 & 0.03 & 0.17 & 0.2 & 0.6
\end{array}\right), \\
B_{7} & =W_{7} R_{7}=\left(\begin{array}{lllll}
0 & 0.05 & 0.05 & 0.38 & 0.52
\end{array}\right), \\
B_{8} & =W_{8} R_{8}=\left(\begin{array}{lllll}
0 & 0.27 & 0.12 & 0.34 & 0.27
\end{array}\right), \\
B_{9} & =W_{9} R_{9}=\left(\begin{array}{lllll}
0 & 0.09 & 0.18 & 0.4 & 0.33
\end{array}\right) .
\end{aligned}
$$




$$
R_{0}=\left[\begin{array}{l}
B_{1} \\
B_{2} \\
B_{3} \\
B_{4} \\
B_{5} \\
B_{6} \\
B_{7} \\
B_{8} \\
B_{9}
\end{array}\right]=\left[\begin{array}{ccccc}
0 & 0.01 & 0.18 & 0.56 & 0.26 \\
0 & 0.15 & 0.25 & 0.32 & 0.29 \\
0 & 0.28 & 0.3 & 0.12 & 0.29 \\
0 & 0.02 & 0.28 & 0.42 & 0.28 \\
0 & 0.01 & 0.11 & 0.29 & 0.5 \\
0 & 0.03 & 0.17 & 0.2 & 0.6 \\
0 & 0.05 & 0.05 & 0.38 & 0.52 \\
0 & 0.27 & 0.12 & 0.34 & 0.27 \\
0 & 0.09 & 0.18 & 0.4 & 0.33
\end{array}\right]
$$

Thus we get membership grade $B_{0}$ :

$$
B_{0}=W_{0} R_{0}=\left(\begin{array}{lllll}
0 & 0.12 & 0.17 & 0.37 & 0.33
\end{array}\right)
$$

Here is the evaluation result based on all factors. The conclusion of the comprehensive evaluation can be obtained by the maximum membership principle. Generally, international student satisfaction is graded as satisfaction since 37\% and $33 \%$ of students graded their education in China as satisfied and very satisfied. $12 \%$ and $17 \%$ of students considered their education in China as unsatisfied and very unsatisfied.

\section{Conclusions and Implications}

\subsection{Conclusions}

This study constructs a framework and uses the fuzzy analytical hierarchy process method to determine the weight for each factor. the result shows that $33 \%$ of students are very satisfied, $37 \%$ are satisfied, $17 \%$ are neutral, $12 \%$ are unsatisfied and no one is very unsatisfied with their education. According to the maximum membership principle, international students are generally happy about their education. According to the survey, obviously, we see that several factors account for international student satisfaction in China. Those factors are student service, perceived value, curriculum and teaching, registration service, campus environment, fairness, career service, social integration and learning.

Furthermore, this study reveals that if we rank sub-criteria for evaluating international student satisfaction, then student service $<$ perceived value $<$ curriculum and teaching $<$ registration service $<$ campus environment $<$ fairness $<$ career service $<$ social integration $<$ learning. It can be found that people are least happy about student service, and then perceived value and lastly curriculum teaching.

\subsection{Implications}

The research suggests that institutions need to make more efforts to improve student service, curriculum design and the quality of teaching. More implications will be given with regard to higher education conditions in China in those aspects.

Recently, higher education institutions have been recruiting an increasing number of international students, which gives more challenge to the current 
student service system. The student service department has been working to build more international student apartments, to recruit more student office workers to meet demands. COVID-19 pandemic diverted traditional in-class teaching to online teaching, which highlights the importance of online teaching and learning. On top of that, the English competency of teachers has remained as a complaint. Not only teachers but service workers are also expected to be competent in English as communication problems arising from English incompetency have also made students feel hard to fix into a new learning environment. With those problems, the fact is that it's hard and expensive to hire people who can speak good English. Proficient English-speakers would be more willing to do more challenging jobs with better payment.

Dorms have been another complaint. International students have been forbidden to live off-campus. The problem is that schools are incapable of providing sufficient apartments to an increasing number of international students. Regularities have to be modified to meet student demand; institutions or universities could work with commercial companies to build more off-campus student apartments to solve the problem.

Student service still has space for improvement. International students complain more about curriculum and teachers. Most international students in China are from non-English-speaking countries. Most of them are not proficient in Chinese. The problem is that language stands in the way to better communication. However, considering English has become a lingua franca in the academic world, bilingual teachers are favored over those who can speak only Chinese. Institutions have to make more policies to recruit bilingual teachers or teachers who have overseas studying experience. Moreover, Chinese teachers still dominate the class by giving lectures, which is not very popular among international students. International students want to be more active and get involved more in class. Chinese teachers need to consider new approaches to impart knowledge in the class.

Though this study tries an approach to investigate what makes international student satisfaction in a structured and analytical way. But it should be noted that AHP has its drawbacks in the inability of handling inherent uncertainty. Still, APH is undeniably an effective way of investigating and understanding the complexities of decisions. This study might give us more insight as to what makes international student satisfaction in China and gives policymakers more reference as to how to manage international students.

\section{Acknowledgements}

This work is supported by the Hubei Provincial Department of Education. (2020669) and Hubei University of Education.

\section{Conflicts of Interest}

The authors declare no conflicts of interest. 


\section{References}

[1] Garciaaracil, A. (2009) European Graduates' Level of Satisfaction with Higher Education. Higher Education, 57, Article No. 1.

https://doi.org/10.1007/s10734-008-9121-9

[2] Elliott, K.M. and Healy, M. A. (2001) Key Factors Influencing Student Satisfaction Related to Recruitment and Retention. Journal of Marketing for Higher Education, 10, 1-11. https://doi.org/10.1300/J050v10n04_01

[3] Saaty, T.L. (1980) The Analytic Hierarchy Process: Planning, Priority Setting, Resource Allocation. McGraw-Hill International Book Co., NY.

[4] Liu, Y., Eckert, C.M. and Earl, C. (2020) A Review of Fuzzy AHP Methods for Decision-Making with Subjective Judgements. Expert Systems with Applications, 161, Article No. 113738. https://doi.org/10.1016/j.eswa.2020.113738

[5] Kuh, G.D. and Hu, S. (2001) The Effects of Student-Faculty Interaction in the 1990s. The Review of Higher Education, 24, 309-332. https://doi.org/10.1353/rhe.2001.0005

[6] Sojkin, B., Bartkowiak, P. and Skuza, A. (2012) Determinants of Higher Education Choices and Student Satisfaction: The Case of Poland. Higher Education, 63, 565-581. https://doi.org/10.1007/s10734-011-9459-2

[7] Wilkins, S. and Balakrishnan, M.S. (2013) Assessing Student Satisfaction in Transnational Higher Education. International Journal of Educational Management, 27, 143-156. https://doi.org/10.1108/09513541311297568

[8] Yusoff, M., Mcleay, F. and Woodruffe-Burton, H. (2015) Dimensions Driving Business Student Satisfaction in Higher Education. Quality Assurance in Education, 23, 86-104. https://doi.org/10.1108/QAE-08-2013-0035

[9] Alemu, A.M. and Cordier, J. (2017) Factors Influencing International Student Satisfaction in Korean Universities. International Journal of Educational Development, 57, 54-64. https://doi.org/10.1016/j.ijedudev.2017.08.006

[10] Kwon, S., Kim, O. and Lee, Y. (2018) Effects of Students' Satisfaction with School Meal Programs on School Happiness in South Korea. Nutrition Research and Practice, 12, 342-347. https://doi.org/10.4162/nrp.2018.12.4.342

[11] Li, X.J. and Lee, J. (2018) Acquisitions or Mergers? International Students' Satisfaction with Work Availability. Journal of Student Affairs Research and Practice. 55, 91-104. https://doi.org/10.1080/19496591.2017.1369421

[12] Chen, Q.T. and Miao, Q.Q. (2016) Study on the Status of International Students' Satisfaction with the Quality of Higher Education Service. Proceedings of the 2016 International Conference on Education, Management Science and Economics, Singapore, 26-28 December 2016, 375-378.

https://doi.org/10.2991/icemse-16.2016.94

[13] Ding, X. (2016) Exploring the Experiences of International Students in China. Journal of Studies in International Education, 20, 21-45.

https://doi.org/10.1177/1028315316647164 